\title{
Phylogenetic Relationships in the Genus Rosa Revisited Based on rpl16, trnL-F, and atpB-rbcL Sequences
}

\author{
Chengyuan Liu
}

Co-Innovation Center for Sustainable Forestry in Southern China, College of Biology and the Environment, Nanjing Forestry University, 159 Longpan Road, Nanjing 210037, China; and Department of Horticulture, Shenzhen Park Service, 257 Qiaocheng Road, Shenzhen 518040, China

\section{Guoliang Wang}

Jiangsu Provincial Commission of Agriculture, 8 Moonlight Square, Nanjing 210036, China

\section{Hui Wang}

Department of Horticulture, Shenzhen Park Service, 257 Qiaocheng Road, Shenzhen 518040, China

\section{Tao Xia}

Co-Innovation Center for Sustainable Forestry in Southern China, College of Biology and the Environment, Nanjing Forestry University, 159 Longpan Road, Nanjing 210037, China

\section{Shouzhou Zhang}

Fairylake Botanical Garden, Shenzhen \& Chinese Academy of Sciences, 160 Xianhu Road, Shenzhen 518004, China

\section{Qigang Wang \\ Yunnan Key Laboratory for Flower Breeding, Flower Research Institute, Yunnan Academy of Agricultural Sciences, 2238 Beijing Road, Kunming 650205, China}

\section{Yanming Fang ${ }^{1}$}

Co-Innovation Center for Sustainable Forestry in Southern China, College of Biology and the Environment, Nanjing Forestry University, 159 Longpan Road, Nanjing 210037, China

Additional index words. Rosa, phylogeny, $r p l 16$, trnL-F, atpB-rbcL

\begin{abstract}
Three chloroplast DNA (cpDNA) sequences [the rpl16 intron, the trnL-F, and $a t p B-r b c L$ intergenic spacer $(I G S)$ ] were employed to study phylogenetic relationships in the genus Rosa. Phylogenetic analyses using these three concatenated sequences were performed using maximum parsimony (MP) and Bayesian inference (BI) methods. Both analyses results suggest that the molecular phylogeny conforms closely to the conventional classification of botanical sections. Morphological similarities between $R$. sects. Synstylae and Chinenses, and $R$. sects. Rosa and Carolinae are corroborated on the molecular level in our analyses. Four taxa from $R$. sect. Pimpinellifoliae are further divided into two small clades, which reflect the morphological characters for these species on a molecular level. Whereas three accessions of $R$. foetida from $R$. sect. Pimpinellifoliae form a separate clade. $R$. $\times$ fortuniana forms a clade with $R$. laevigata based on its maternal inheritance of cpDNA. $R$. $\times$ cooperii is hypothesized to be a hybrid with seed parent from $R$. sects. Synstylae and Chinenses. And $R$. roxburghii should be classified as a section within the $R$. subgen. Rosa, rather than being treated as its own subgenus, based on molecular analyses.
\end{abstract}

The genus Rosa L. comprises $\approx 200$ species distributed widely throughout the temperate and subtropical regions of the northern hemisphere ( $\mathrm{Ku}$ and Robertson, 2003; Rehder, 1940; Wissemann, 2003). However, less than 10 species have likely contributed to modern cultivated roses (Wylie, 1954). The genetic background of cultivated roses is, therefore, very narrow compared with the abundant germplasm resources available in this genus (Bruneau et al., 2007; Matsumoto et al., 1998). Genetic relationship studies within the genus based on morphology are difficult owing to intraspecific variability, polyploidy, and interspecific hybridization (Bruneau et al., 2007; Wissemann, 2003).
Conventional taxonomy (Rehder, 1940; Wissemann, 2003) divides the genus into four subgenera: $R$. subgen. Hulthemia (Dumort.) Focke, $R$. subgen. Platyrhodon (Hurst) Rehder, $R$. subgen. Hesperhodos Cockerell, and $R$. subgen. Rosa. The first three subgenera are monotypic or contain two species, whereas the $R$. subgen. Rosa contains all the remaining species and is divided into 10 sections: $[R$. sect. Pimpinellifoliae (DC.) Ser., $R$. sect. Cinnamomeae (DC.) Ser., $R$. sect. Synstylae DC., $R$. sect. Indicae Thory, $R$. sect. Banksianae Lindl., $R$. sect. Laevigatae Thory, R. sect. Bracteatae Thory, R. sect. Gallicanae (DC.) Ser., $R$. sect. Carolinae Crép., and $R$. sect. Caninae (DC.) Ser.] However, species within this genus are only divided into $R$. subgen. Hulthemia and $R$. subgen. Rosa in Flora of China (Ku and Robertson, 2003), where the $R$. subgen. Platyrhodon is treated as $R$. sect. Microphyllae Crépin in $R$. subgen. Rosa (Crépin, 1889; $\mathrm{Ku}$ and Robertson, 2003), and the $R$. subgen. Hesperhodos, $R$. sects. Carolinae and Caninae are not included in this classification system at all.

Phylogenetic relationships on a molecular level within this genus have previously been investigated based on restriction/amplified fragment length polymorphism analyses (Koopman et al., 2008; Matsumoto et al., 1997), random amplified polymorphic DNA analyses (Debener et al., 1996; Jan et al., 1999; Millan et al., 1996), and microsatellite analyses (Scariot et al., 2006; Tang et al., 2008). Furthermore, nucleotide sequence data have increasingly been used in phylogenetic studies of this genus, for instance, the internal transcribed spacer (ITS) of nuclear ribosomal DNA (nrDNA) (Matsumoto et al., 2000; Wissemann and Ritz, 2005; Wu et al., 2001), the cpDNA matK gene (Matsumoto et al., 1998; Wu et al., 2000), the cpDNA $a t p B-r b c L I G S$ (Wissemann and Ritz, 2005), the combined cpDNA trnL-F and psbA-trnH IGS (Bruneau et al., 2007), and the combined nrDNA ITS and cpDNA matK gene (Qiu et al., 2012). Although Rosa species phylogeny has been researched using these different markers, when comparing with this notoriously complex genus, its resolution remains poor. Additionally, contradictory results exist between these previous investigations.

In this study, we analyzed 48 genotypes including several mutations and variations within this genus by using the cpDNA rpl16 intron, the $\operatorname{trn} L-F$, and $a t p B-r b c L I G S$ sequences, which initial analyses have shown to be reasonably variable. Several species used in the present study were not included in previous analyses. Moreover, there are few reports regarding phylogenetic relationships in Rosa that combine three or more different DNA sequence regions (Fougère-Danezan et al., 2015; Leus et al., 2004; Zhu et al., 2015). The objectives of this study are to construct a robust, well-resolved phylogeny for Rosa accessions derived from multiple molecular marker systems, and to provide suggestions regarding the taxonomic classification by comparing the present findings 
with results from previous phylogenetic studies of this genus. For the purpose of this research, $R$. roxburghii Tratt. is classified in $R$. sect. Microphyllae following Crépin (1889) and $\mathrm{Ku}$ and Robertson (2003), thus, eleven sections are represented by the taxa in our investigation. Besides, in this study $R$. sect. Chinenses (DC.) Ser. was used instead of $R$. sect. Indicae since the former is the oldest valid name while the latter is a synonym (Seringe, 1818; Thory, 1820). And following the proposal that the type species of this genus is $R$. cinnamomea L. (Jarvis, 1992), R. sect. Rosa was used instead of $R$. sect. Cinnamomeae in this study.

\section{Materials and Methods}

Plant materials. The list of wild roses used in this study is provided in Table 1. Sample numbers 1-5, 8-11, 13-24, and 2946 were grown in the field at the Rose Trial Station of the Shenzhen Park Service, Guangdong, China. Sample numbers 6, 7, 14, 15, 26 , and 27 were grown in the field at the Flower Research Institute nursery, Yunnan Academy of Agricultural Sciences, Yunnan, China. Sample numbers 12, 28, 47, and 48 were grown in the field at the Shanghai Chenshan Botanical Garden, Shanghai, China. Morphological traits and literature descriptions were used to confirm the identity of specimen (Ku and Robertson, 2003; Rehder, 1940; Wissemann, 2003). Four species from the related genera Rubus L. and Spiraea L. (Rubus lambertianus Ser., Rubus hirsutus Thunb., Rusbus corchorifolius L., and Spiraea trilobata $\mathrm{L}$.) were chosen as the out-group and samples were collected from Zijin Mountain, Jiangsu, China. Young leaves of all accessions were collected and froze at $-80^{\circ} \mathrm{C}$ for storage until use. All the voucher samples were preserved and archived in the Herbarium of Nanjing Forestry University.

DNA extraction, polymerase chain reaction (PCR) amplification, and sequencing. Seven DNA regions from three genomes were examined for their variability among the accessions: the ITS of nrDNA, the rpllo intron, the $\operatorname{trn} L-F$ and $a t p B-r b c L I G S$ of cpDNA, and the $c c b 256$, cox2, and nadl genes of mitochondrial DNA (mtDNA). Among these seven regions, the ITS region was abandoned owing to extensive

Received for publication 1 May 2015. Accepted for publication 9 Sept. 2015.

We thank Hongying Jian and Xianqin Qiu of the Flower Research Institute, Yunnan Academy of Agricultural Sciences, and Yang Liu and Zhengzhi Jiang of the Shanghai Botanical Garden for supplying some of the species used in this study. We thank the publications coordinator Tecola Forbes for assistance with manuscript preparation. We are grateful to two anonymous reviewers for valuable suggestions regarding the manuscript. This work was supported by funds from the Priority Academic Program Development of Jiangsu High Education Institutions (PAPD), and the Urban Administration Bureau of Shenzhen (No. 201008).

${ }^{1}$ Corresponding author. E-mail: ymfang_nfu@ 126.com. sequence polymorphisms within a single genotype (Matsumoto et al., 2000; Wissemann and Ritz, 2005; Zhu et al., 2015), and the mtDNA $c c b 256$, cox2, and nad1 genes were abandoned because of a lack of informative sites in the data matrix $(0.4 \%, 0.3 \%$, and $0.6 \%$, respectively, excluding the out-group, unpublished results). The three cpDNA regions were comparatively variable and were used for phylogenetic analyses.

Total DNA from the leaves of individual plants was isolated using a Genomic DNA Extraction Kit (DP305; TianGen Co., Ltd, Beijing, China). The three cpDNA regions were amplified by PCR in a reaction mixture of $25-\mu \mathrm{L}$ total volume, containing $10 \mathrm{~mm}$ Tris- $\mathrm{HCl}(\mathrm{pH} 8.0), 50 \mathrm{~mm} \mathrm{KCl}, 1.5 \mathrm{~mm}$ $\mathrm{MgCl}_{2}, 200 \mu \mathrm{M}$ deoxynucleotide triphosphates, $2.5 \mathrm{U}$ Taq-DNA polymerase, $50 \mathrm{ng}$ template DNA, and $1.0 \mu \mathrm{M}$ forward and reverse primers of $r p l 16$, trnL-F, and $a t p B-$ $r b c L$, accordingly (Table 2). The amplification conditions for each region were as follows: for rpll6, an initial $4 \mathrm{~min}$ at $95{ }^{\circ} \mathrm{C}$, followed by 32 cycles of $1 \mathrm{~min}$ at $94{ }^{\circ} \mathrm{C}$, $1 \mathrm{~min}$ at $52^{\circ} \mathrm{C}, 1 \mathrm{~min}$ at $72{ }^{\circ} \mathrm{C}$, and $10 \mathrm{~min}$ at $72{ }^{\circ} \mathrm{C}$ for the final extension; for $\operatorname{trn} L-F$, an initial $3 \mathrm{~min}$ at $95^{\circ} \mathrm{C}$, followed by 35 cycles of $30 \mathrm{~s}$ at $95^{\circ} \mathrm{C}, 30 \mathrm{~s}$ at $50^{\circ} \mathrm{C}, 1 \mathrm{~min} 20 \mathrm{~s}$ at $72^{\circ} \mathrm{C}$, and 7 min at $72{ }^{\circ} \mathrm{C}$ for the final extension (Bruneau et al., 2007); and for $a t p B-r b c L$, an initial $3 \mathrm{~min}$ at $95^{\circ} \mathrm{C}$, followed by 30 cycles of $30 \mathrm{~s}$ at $95^{\circ} \mathrm{C}, 45 \mathrm{~s}$ at $48^{\circ} \mathrm{C}, 1 \mathrm{~min}$ at $72{ }^{\circ} \mathrm{C}$, and $5 \mathrm{~min}$ at $72{ }^{\circ} \mathrm{C}$ for the final extension (Wissemann and Ritz, 2005). Amplifications were performed in an Eppendorf thermocycler (Mastercycler Nexus X1). The amplified products were sequenced by Invitrogen (Shanghai, China). Sequencing primers were identical to those used for amplification.

Phylogenetic analyses. The sequences were aligned using Clustal X (Thompson et al., 1997) and checked manually in BioEdit (Hall, 1999). Our three cpDNA sequence alignments were used to construct separate (not shown in this paper) and combined data matrixes. Modeltest (Posada and Crandall, 1998) was used to perform hierarchical likelihood ratio tests to estimate an optimal nucleotide substitution model for use with MrBayes (Ronquist and Huelsenbeck, 2003). The MP method in PAUP* $4.0 \mathrm{~b} 10$ (Swofford, 2002) was used with its heuristic search option to find the most parsimonious trees. Insertions and/or deletions (indels) were included in the matrixes, and the resulting gaps were treated as missing data. Character state changes were all weighted equally. Searches were performed using 1000 replicates for bootstrap analysis (Felsenstein, 1985).

BI using Monte Carlo Markov chain (MCMC) was performed with MrBayes 3.0b4 (Ronquist and Huelsenbeck, 2003). Four incrementally heated simultaneous MCMCs were run over 2,000,000 generations, using the general time reversible nucleotide substitution model with gamma distributed substitution rates, random starting trees, and default nucleotide substitution model starting values. Trees were sampled every 100 generations resulting in an overall sampling of 20,001 trees. The first 1000 "burn-in" trees were excluded from each analysis. A $50 \%$ majority rule consensus tree was computed to obtain estimates of a posteriori probabilities. Two independent analyses were conducted using these initial parameters.

\section{Results}

Sequence analysis. Summary sequence statistics for the three cpDNA regions were presented in Table 3. Among these three regions, the proportion of informative characters was highest in the rpll6 region $(7.6 \%$ and $4.6 \%$, depending on inclusion or exclusion of the out-group, respectively). The percentage of informative characters in the trnL-F and $a t p B-r b c L$ were $3.5 \%$ and $2.4 \%$, within the in-group data matrixes, respectively. These three regions were all relatively easy to align; however, two microsatellites (9-12 $\mathrm{A}^{\prime} \mathrm{s}$ and 8-15 $\mathrm{A}^{\prime} \mathrm{s}$ ) at positions 342353 and 418-432 in the rpll 6 region, and one microsatellite $\left(9-12 \mathrm{~T}^{\prime} \mathrm{s}\right)$ at positions 427 438 in the $t r n L-F$ spacer were excluded from analyses data because these regions could not be reliably aligned (Bruneau et al., 2007).

Phylogenetic analyses. A total of 2610 nucleotides were used for phylogenetic analyses, heuristic searches of combined data matrix including indels produced 285 variable characters and 207 informative characters, between in-group and out-group in the data matrix (Table 3). The heuristic search resulted in 2000 trees, with a tree length of 607 , a consistency index 0.873 , and a retention index of 0.902 . The Bayesian $50 \%$ majority rule consensus of 19,001 trees in stationary phase from the two analyses is presented in Fig. 1. Results from the Bayesian analyses were very similar to those using parsimony.

Both methods suggested that the 48 taxa used in our study should be divided into two major groups. The first group was composed of taxa from $R$. sects. Pimpinellifoliae, Rosa, and Carolinae. Within this group, taxa from $R$. sects. Rosa and Carolinae formed an inner clade, two other clades were set apart and were constituted by taxa both from $R$. sect. Pimpinellifoliae. The second group included all the remaining taxa and was further divided into five clades: the first clade consisted of taxa from $R$. sects. Synstylae, Chinenses, Gallicanae, and Caninae as well as $R$. $\times$ cooperii (sample no. 43 ), the molecular data placed taxa from $R$. sect. Caninae, and $R$. arvensis (sample no. 28) of $R$. sect. Synstylae in a sister relationship to the reminder accessions. The second clade consisted of taxa from $R$. sect. Banksianae, except for $R$. $\times$ fortuniana (sample no. 37), which formed the third clade together with $R$. laevigata (sample no. 42) of $R$. sect. Laegigatae. The fourth clade and the fifth clade contained accessions from $R$. sects. Microphyllae and Bracteatae, respectively.

\section{Discussion}

The 48 taxa phylogeny presented (Fig. 1) based on our three concatenated sequence regions conforms closely to the conventional 


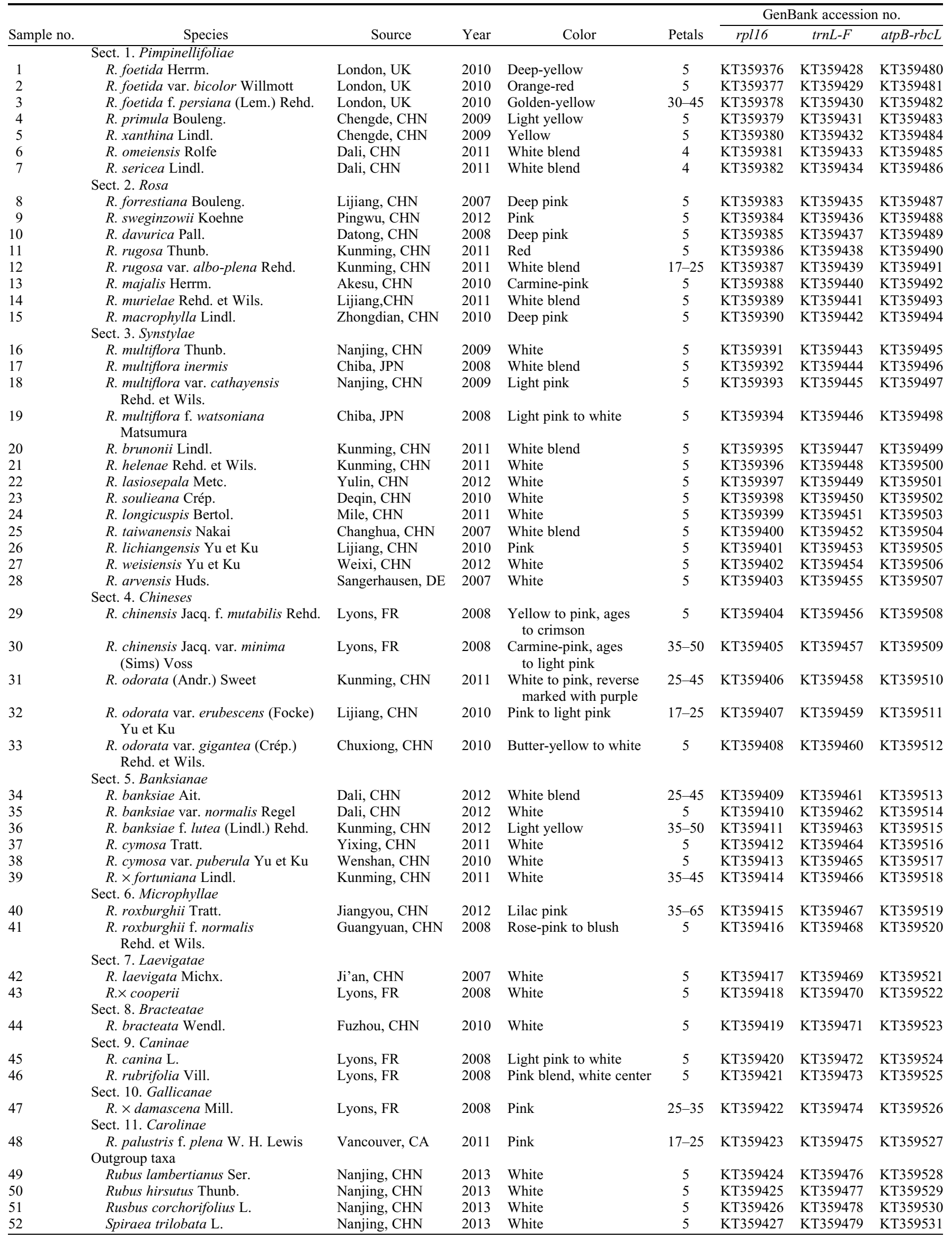


Table 2. Primers for PCR amplification and sequencing.

\begin{tabular}{|c|c|c|c|}
\hline Region & Name & Sequences $\left(5^{\prime}-3^{\prime}\right)$ & References \\
\hline \multirow[t]{2}{*}{ rpl16 } & rpl16F & CCСТTTCATTCTTCССCTATGTTG & Small et al., 1998 \\
\hline & rpl16R & GCTATGCTTAGTGTGCGACTCGTTG & \\
\hline \multirow[t]{2}{*}{$\operatorname{trn} L-F$} & $\operatorname{trnL}$ & CGAAATCGGTAGACGCTACG & Taberlet et al., 1991 \\
\hline & $\operatorname{trnF}$ & ATTTGAACTGGTGACACGAG & \\
\hline \multirow[t]{2}{*}{$a t p B-r b c L$} & 2 & GAAGTAGTAGGATTGATTCT & Savolainen et al., 1994 \\
\hline & 10 & CATCATTATTGTATACTCTTTC & \\
\hline
\end{tabular}

Table 3. Sequence and parsimony analysis statistics for separate and combined chloroplast DNA data sets used in phylogenetic analyses.

\begin{tabular}{|c|c|c|c|c|}
\hline Character & rpl16 & $\operatorname{trn} L-F$ & $a t p B-r b c L$ & Combined data \\
\hline \multicolumn{5}{|l|}{ Length range (bp) } \\
\hline In-group & $891-911$ & $959-968$ & $539-591$ & $2,397-2,463$ \\
\hline Out-group included & $875-911$ & $903-968$ & $539-591$ & $2,317-2,463$ \\
\hline \multicolumn{5}{|l|}{ Aligned length (bp) } \\
\hline Out-group included & 996 & 993 & 621 & 2,610 \\
\hline \multicolumn{5}{|l|}{ Number of indels } \\
\hline In-group & 4 & 2 & 4 & 10 \\
\hline Out-group included & 6 & 9 & 4 & 19 \\
\hline \multicolumn{5}{|l|}{ Variable characters } \\
\hline In-group & $41(4.1 \%)$ & $11(1.1 \%)$ & $13(2.1 \%)$ & $65(3.0 \%)$ \\
\hline Out-group included & $110(11.0 \%)$ & $117(11.8 \%)$ & $58(9.3 \%)$ & $285(11.0 \%)$ \\
\hline \multicolumn{5}{|l|}{ Informative characters } \\
\hline In-group & $46(4.6 \%)$ & $35(3.5 \%)$ & $15(2.4 \%)$ & $96(3.7 \%)$ \\
\hline Out-group included & $76(7.6 \%)$ & $78(7.8 \%)$ & $34(5.5 \%)$ & $188(7.2 \%)$ \\
\hline \multicolumn{5}{|l|}{ Number of trees } \\
\hline Out-group/indels included & 1,998 & 2 & 1,998 & 2,000 \\
\hline \multicolumn{5}{|l|}{ Tree length } \\
\hline Out-group/indels included & 262 & 235 & 107 & 607 \\
\hline \multicolumn{5}{|l|}{ Consistency index } \\
\hline Out-group/indels included & 0.813 & 0.932 & 0.916 & 0.873 \\
\hline \multicolumn{5}{|l|}{ Retention index } \\
\hline Out-group/indels included & 0.861 & 0.948 & 0.928 & 0.902 \\
\hline
\end{tabular}

$\mathrm{bp}=$ base pair.

classification of Rosa botanical sections (Matsumoto et al., 1998; Qiu et al., 2012). For example, five species of the traditional $R$. sect. Banksianae formed a clade in our phylogeny with high posteriori probability and bootstrap support $(100 \%$ and $86 \%$, respectively). The phylogenetic results are also consistent with other studies in which taxa from genus Rosa are generally divided into two main clades, named Cinnamomeae (Rosa) clade or Clade I, and Synstylae clade or Clade II (Bruneau et al., 2007; FougèreDanezan et al., 2015). However, notable exceptions exist.

Three accessions (sample no. 1-3) of $R$. foetida were separated from the other taxa (sample no. 4-7) of $R$. sect. Pimpinellifoliae. This result has also been found in previous studies (Bruneau et al., 2007; FougèreDanezan et al., 2015; Matsumoto et al., 1998). The fertility of tetraploid $R$. foetida is strikingly low (Roberts, 1977; Rowley, 1967), and it may represent an ancient hybrid of unknown parentage (Wylie, 1954). Our clustering results resolved the other four taxa (sample no. 4-7) of $R$. sect. Pimpinellifoliae as a sister relationship to the taxa from $R$. sects. Rosa and Carolinae. While in a more extensive taxon sampling of $R$. sect. Pimpinellifoliae made by Fougère-Danezan et al. (2015), several species (R. spinosissima L., $R$. tsinglingensis Pax \& K. Hoffm., R. farreri Stapf ex Cox, and R. koreana Kom.) of this section are embedded in the Rosa-Carolinae clade. Moreover, the above four taxa are further divided into two small clades based on our molecular analyses (Fig. 1). In Flora of China (Ku and Robertson, 2003), $R$. primula (sample no. 4) and $R$. xanthina (sample no. 5) belong to series Spinosissimae with five petals, whereas $R$. omeiensis (sample no. 6) and $R$. sericea (sample no. 7) belong to series Sericeae with four petals. Our molecular results seem to well reflect the morphological peculiarities of these species in $R$. sect. Pimpinellifoliae. Similar results have also been obtained in previous molecular phylogenetic studies in this genus (Fougère-Danezan et al., 2015; Matsumoto et al., 1998; Qiu et al., 2012).

The Carolinae section should be merged with the Rosa section according to several authors (Bruneau et al., 2007; FougèreDanezan et al., 2015; Koopman et al., 2008; Matsumoto et al., 1998; Scariot et al., 2006; Takeuchi et al., 2000). This result was confirmed in our analysis. Morphologically $R$. sects. Rosa and Carolinae can be distinguished by week differences: the sepals are usually upright and persistent in $R$. sect. Rosa vs. reflected and deciduous in $R$. sect. Carolinae (Rehder, 1940; Wissemann, 2003). However, the distinction of this character is not substantiated on molecular level in these two sections. R. palustris f. plena (sample no. 48), traditionally placed in the Carolinae section (Table 1), formed a group with all the accessions (samples no. 8-15) of $R$. sect. Rosa in our study with $100 \%$ posteriori probability and $91 \%$ bootstrap support (Fig. 1).

Taxa from $R$. sect. Synstylae were clustered with accessions of $R$. sect. Chinenses in the phylogeny (Fig. 1). Several authors have already pointed out the close relationship between $R$. sects. Synstylae and Chinenses (Bruneau et al., 2007; Fougère-Danezan et al., 2015; Jan et al., 1999; Matsumoto et al., 1998, 2000; Millan et al., 1996; Qiu et al., 2012; Wissemann and Ritz, 2005; Wu et al., 2000; Zhu et al., 2015). The morphological similarity of these two sections also concurs with our molecular study, for both sections have adnate and persistent stipules, and exserted styles, taxa of $R$. sect. Chinenses only lack the connected styles ( $\mathrm{Ku}$ and Robertson, 2003; Rehder, 1940). It appears these two sections are not monophyletic in the phylogeny in our study (Fig. 1). Similar results have been reported in several previous studies (Bruneau et al., 2007; Fougère-Danezan et al., 2015; Matsumoto et al., 1998; Qiu et al., 2012; Wissemann and Ritz, 2005; Wu et al., 2000; Zhu et al., 2015), but there are also contrary studies suggested that these two sections are independently monophyletic (Jan et al., 1999; Matsumoto et al., 2000; Millan et al., 1996). Moreover, taxa from $R$. sect. Synstylae can be further divided into series Multiflorae and Brunonianae, respectively, depending on the stipules are pectinate or entire according to Flora of China (Ku and Robertson, 2003). However, this morphological character was not discovered in our study, nor in a recent report by Zhu et al. (2015). Besides, three samples of $R$. odorata ( $R$. sect. Chinenses, sample no. 31-33) formed an inner clade with $R$. brunonii (sample no. 20), $R$. helenae (sample no. 21), and $R$. weisiensis (sample no. 27) of $R$. sect. Synstylae, is similar to two recent studies (Fougère-Danezan et al., 2015; Zhu et al., 2015). R. chinensis var. mutabilis (sample no. 29) was first reported in our study, and it presented in the Synstylae-Chinenses clade with an unresolved position (Fig. 1), which may be due to its remarkable variation in the flower color during blooming (Table 1). Nevertheless, more comprehensive molecular studies are still needed to ascertain the position of this peculiar species.

Within the Synstylae-Chinenses clade, $R$. $\times$ damascena (sample no. 47) from $R$. sect. Gallicanae was merged with $R$. sects. Synstylae and Chinenses, while two taxa of $R$. sect. Caninae, together with $R$. arvensis (sample no. 28), formed a separate small clade (Fig. 1). The results show that $R$. sect. Gallicanae, rather than $R$. sect. Caninae, is a closer relative to $R$. sects. Synstylae and Chinenses, and that $R$. sect. Caninae appears to be sister to the Synstylae-Chinenses clade. Several previous studies obtained similar results based on the research on $R$. gallica L. of $R$. sect. Gallicanae (Koopman et al., 


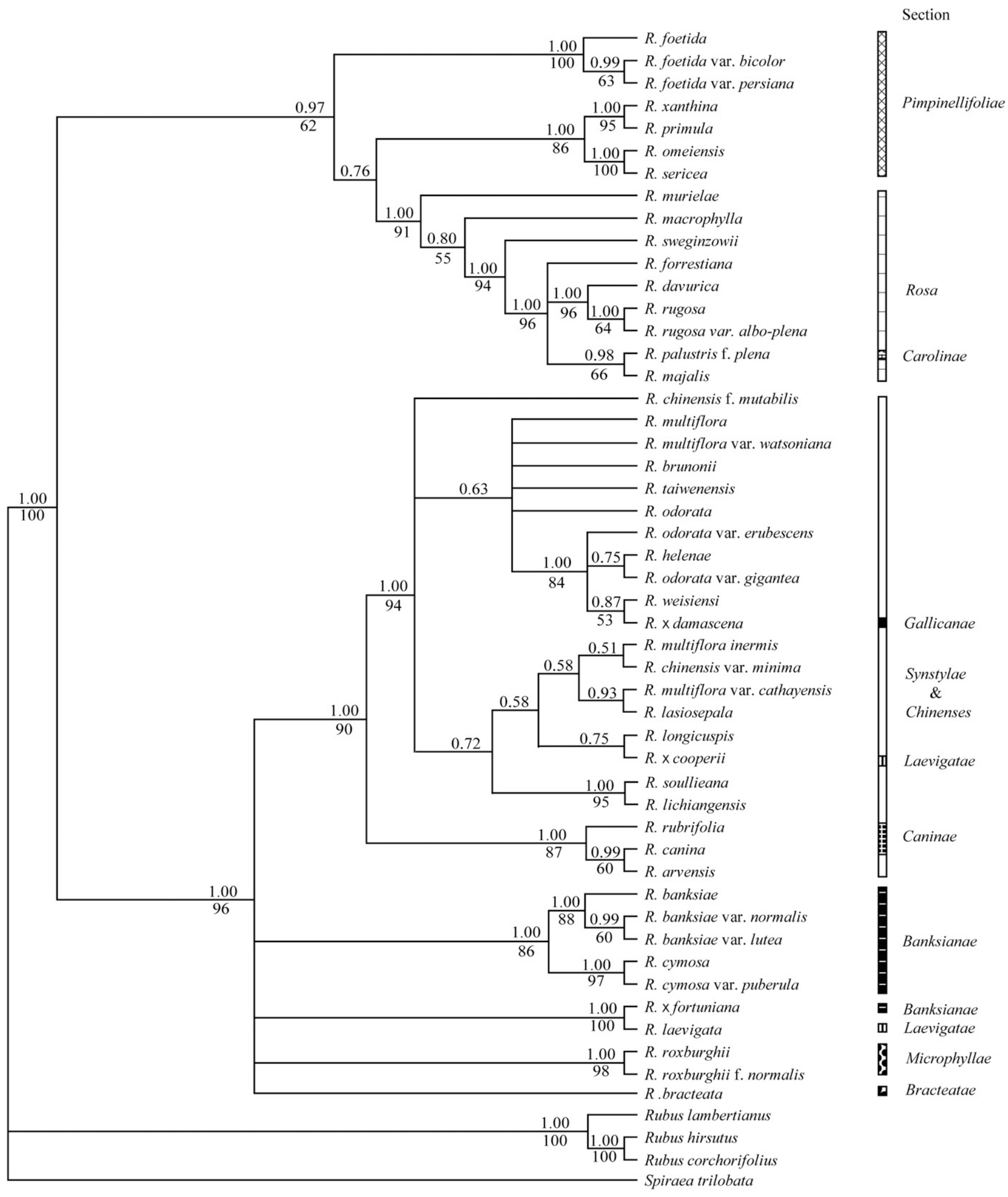

Fig. 1. Bayesian 50\% majority rule consensus of trees sampled in the stationary phase of two analyses. Values above the branches are the posterior probabilities for each clade, below the branches are bootstrap values $(>50 \%)$ for the same clades found during parsimony searches.

2008; Millan et al., 1996; Scariot et al., 2006; Wissemann and Ritz, 2005). However, in recent studies, $R$. gallica formed a clade with taxa from $R$. sect. Caninae, and both of these two sections appear sister relationship to the Synstylae-Chinenses clade (Fougère-Danezan et al., 2015; Zhu et al., 2015). $R$. $\times$ damascena is thought to be a hybrid with three parents of wild species, and $R$. moschata Herrm. of $R$. sect. Synstylae is considered the female parent (Iwata et al., 2000; Millan et al., 1996). This viewpoint is supported by Takeuchi et al. (2000) whose study showed that $R$. odorata var. gigantea,
$R$. moschata, and $R$. ×damascena were grouped into one clade apart from $R$. sect. Gallicanae.

It is interesting that the only European species of $R$. sect. Synstylae, $R$. arvensis, together with $R$. canina (sample no. 45) of $R$. sect. Caninae formed a small clade in our 
analysis (Fig. 1); this result is consistent with previous studies (Wissemann and Ritz, 2005; Zhu et al., 2015), and it also helps to explain why the origin of $R$. $\times a l b a \mathrm{~L}$. is ambiguous, because they are both hypothetical parents of R. $\times a l b a$ (Klastersky, 1968; Millan et al., 1996). Furthermore, the origin of $R$. $\times$ cooperii (sample no. 43 ) is still in dispute. $R$. $\times$ cooperii is thought to be a seedling of $R$. laevigata (Beales, 1985), or a natural hybrid between a seed parent, $R$. odorata var. gigantea, and a pollen parent, $R$. laevigata (Young and Schorr, 2007). However, on the basis of our cpDNA molecular data, it formed a clade with $R$. odorata var. gigantea (Synstylae-Chinenses clade), rather than being clustered with $R$. laevigata (Fig. 1). This result suggests that the seed parent of $R$. ×cooperii might not be $R$. laevigata considering the maternal inheritance of cpDNA in Rosa (Matsumoto et al., 1998). Meanwhile, since this species was also not clustered with $R$. odotata var. gigantea in the Synstylae-Chinenses clade, it could not be confirmed whether the seed parent of $R$. ×cooperii is $R$. odorata var. gigantea, but is possibly a parent from $R$. sects. Synstylae and Chinenses.

Our clustering results resolved five samples (sample no. 34-38) of $R$. sect. Banksianae as monophyletic and as sisters to the Synstylae-Chinense clade, without considering the position of $R$. ×fortuniana (sample no. 39). Similar results were obtained in previous studies (Fougère-Danezan et al., 2015; Qiu et al., 2012; Wu et al., 2001). R. ×fortuniana, which is traditionally placed in the $R$. sect. Banksianae, formed a clade with $R$. laevigata with $100 \%$ posteriori probability and $100 \%$ bootstrap confidence in our plastid sequence analyses (Fig. 1). $R$. $\times$ fortuniana is thought to be a hybrid between a $R$. laevigata seed parent and a $R$. banksiae pollen parent, and its cpDNA matK sequence matches that of $R$. laevigata, not $R$. banksiae (Matsumoto et al., 2001). This matK sequence result is consistent with our molecular data. $R$. sects. Laevigatae and Bracteatae were also resolved as sister relationship to the Synstylae-Chinense clade in the second group in our study. Similar results were indicated in other studies for $R$. sect. Laevigatae (Jan et al., 1999; Zhu et al., 2015), for $R$. sect. Bracteatae (Wissemann and Ritz, 2005), or for the both sections (FougèreDanezan et al., 2015; Qiu et al., 2012). Furthermore, R. sects. Banksianae, Laevigatae, and Bracteatae are morphologically united in a large clade according to the free and deciduous stipules (Rehder, 1940). However, $R$. sect. Banksianae discriminates from $R$. sect. Bracteatae (which is readily featured by its woolly or tomentose young receptacle and branchlet) by the nonpubescent receptacle and branchlet, and discriminates from $R$. sect. Laevigatae by the reflexed and deciduous sepals. In addition, the stipules of $R$. sect. Bracteatae are deeply incised, which obviously differs from the other two sections. Several previous analyses also indicate that these three sections are distantly related to each other (Fougère-Danezan et al., 2015; Jan et al., 1999; Qiu et al., 2012). So it seems that the morphological characterization of free and deciduous stipules in these three sections indicates not synapomorphy but convergence or plesiomorphy (Wissemann and Ritz, 2005). Besides, $R$. roxburghii (sample no. 40) and $R$. roxburghii f. normalis (sample no. 41) formed a clade, and in parallel with $R$. sects. Banksianae, Laevigatae, and Bracteatae (Fig. 1). This agrees with previous suggestions that $R$. roxburghii should be placed on a sectional level (Crépin, 1889; Fougère-Danezan et al., 2015; Jan et al., 1999; Koopman et al., 2008; $\mathrm{Ku}$ and Robertson, 2003; Wissemann and Ritz, 2005), rather than being classified as a subgenus (Rehder, 1940; Wissemann, 2003).

In summary, our phylogenetic reconstruction (Fig. 1) derived from the combined three cpDNA data for 48 genotypes shows substantial consistency with the conventional classification of infrageneric sections (Table 1). However, the results are mostly not consistent with the conventional taxonomy in a better sampling of both taxa and molecular markers (Fougère-Danezan et al., 2015; Zhu et al., 2015). The differences might be caused by the hybridization (genetic introgression) and/or polyploidization existing among the taxa of this genus. For instance, R. lichiangensis (sample no. 26) has been confirmed to be a hybrid species (Zhu et al., 2015), and the decaploid $R$. praelucens Byhouwer is also regarded as an allopolyploid resulting from hybridization (Fougère-Danezan et al., 2015; Jian et al., 2010). Moreover, chloroplast markers ignore hybridization (because of their maternal inheritance), and concerted evolution and homogenization of parental polymorphism exist in the ITS region of nrDNA. Therefore, low/single copy nuclear genes, such as those used by Zhu et al. (2015), should be employed in future studies to better understand this complex genus.

\section{Literature Cited}

Beales, P. 1985. Classic roses: An illustrated encyclopedia and grower's manual of old roses, shrub roses, and climbers, p. 403. Collins Harvill, London, UK.

Bruneau, A., J.R. Starr, and S. Joly. 2007. Phylogenetic relationships in the genus Rosa: New evidence from chloroplast DNA sequences and an appraisal of current knowledge. Syst. Bot. 32:366-378

Crépin, F. 1889. Sketch of a new classification of roses. J. Roy. Hort. Soc. 11:337-352.

Debener, T., C. Bartels, and L. Mattiesch. 1996. RAPD analysis of genetic variation between a group of rose cultivars and selected wild rose species. Mol. Breeding 2:321-327.

Felsenstein, J. 1985. Confidence limits on phylogenies: An approach using the bootstrap. Evolution 39:783-791.

Fougère-Danezan, M., S. Joly, A. Bruneau, X.F. Gao, and L.B. Zhang. 2015. Phylogeny and biogeography of wild roses with specific attention to polyploids. Ann. Bot. (Lond.) 115:275-291.

Hall, T.A. 1999. BioEdit: A user friendly biological sequence alignment editor and analysis program for Windows 95/98/NT. Nucl. Acids Symp. Ser. 41:95-98.

Iwata, H., T. Kato, and S. Ohno. 2000. Triparental origin of Damask roses. Gene 259:53-59.

Jan, C.H., D.H. Byrne, J. Manhart, and H. Wilson. 1999. Rose germplasm analysis with RAPD markers. HortScience 34:341-345.
Jarvis, C.E. 1992. Seventy-two proposals for the conservation of types of selected Linnaean generic names, the report of Subcommittee $3 \mathrm{C}$ on the lectotypification of Linnaean generic names. Taxon 41:552-583.

Jian, H.Y., H. Zhang, K.X. Tang, S.F. Li, Q.G. Wang, T. Zhang, X.Q. Qiu, and H.J. Yan. 2010. Decaploidy in Rosa praelucens Byhouwer (Rosaceae) endemic to Zhongdian Plateau, Yunnan, China. Caryologia 63:162-167.

Klastersky, I. 1968. Rosa L., p. 25-32. In: T.G. Tutin, V.H. Heywood, N.A. Burges, D.M. Moore, D.H. Valentine, S.M. Walters, and D.A. Webb (eds.). Flora Europaea, vol. 2. Cambridge University Press, London, UK.

Koopman, W.J.M., V. Wissemann, K. De Cock, J. Van Huylenbroeck, J. De Riek, G.J.H. Sabatino, D. Visser, B. Vosman, C.M. Ritz, B. Maes, G. Werlemark, H. Nybom, T. Debener, M. Linde, and M.J.M. Smulders. 2008. AFLP markers as a tool to reconstruct complex relationships: A case study in Rosa (Rosaceae). Amer. J. Bot. 95:353-366.

Ku, T.C. and K.R. Robertson. 2003. Rosa (Rosaceae), p. 339-381. In: Z.Y. Wu and P.H. Raven (eds.). Flora of China, vol. 9. Science Press, Beijing, China.

Leus, L., F. Jeanneteau, J. Van Huylenbroeck, E. Van Bockstaele, and J. De Riek. 2004. Molecular evaluation of a collection of rose species and cultivars by AFLP, ITS, rbcL and matK. Acta Hort. 651:141-147.

Matsumoto, S., M. Kouchi, and H. Fukui. 2000. Phylogenetic analyses of the subgenus Eurosa using the ITS nrDNA sequence. Acta Hort. 521:193-202.

Matsumoto, S., M. Kouchi, J. Yabuki, M. Kusunoki, Y. Ueda, and H. Fukui. 1998. Phylogenetic analyses of the genus Rosa using the matK sequence: Molecular evidence for the narrow genetic background of modern roses. Sci. Hort. 77:73-82.

Matsumoto, S., H. Nishio, Y. Ueda, and H. Fukui. 2001. Phylogenetic analyses of genus Rosa: Polyphyly of section Pimpinellifoliae and origin of Rosa $\times$ fortuniana Lindl. Acta Hort. 547:357-363.

Matsumoto, S., H. Wakita, and H. Fukui. 1997. Molecular classification of wild roses using organelle DNA probes. Sci. Hort. 68:191-197.

Millan, T., F. Osuna, S. Cobos, A.M. Torres, and J.I. Cubero. 1996. Using RAPDs to study phylogenetic relationships in Rosa. Theor. Appl. Genet. 92:273-277.

Posada, D. and K.A. Crandall. 1998. Modeltest: Testing the model of DNA substitution. Bioinformatics 14:817-818.

Qiu, X.Q., H. Zhang, Q.G. Wang, H.Y. Jian, H.J. Yan, T. Zhang, J.H. Wang, and K.X. Tang. 2012. Phylogenetic relationships of wild roses in China based on nrDNA and matK data. Sci. Hort. 140:45-51.

Rehder, A. 1940. Manual of cultivated trees and shrubs. 2nd ed. MacMillan, New York, NY.

Roberts, A.V. 1977. Relationship between species in the genus Rosa, section Pimpinellifoliae. Bot. J. Linn. Soc. 74:309-328.

Ronquist, F. and J.P. Huelsenbeck. 2003. MrBayes 3: Bayesian phylogenetic inference under mixed models. Bioinformatics 19:1572-1574.

Rowley, G.D. 1967. Chromosome studies and evolution in Rosa. Bul. Jard. Bot. Natl. Belg. $37: 45-52$.

Savolainen, V., J.F. Manen, E. Douzery, and R. Spichiger. 1994. Molecular phylogeny of families related to Celastrales based on $r b c \mathrm{~L} 5^{\prime}$ flanking sequences. Mol. Phylogenet. Evol. 3:27-37. 
Scariot, V., A. Akkak, and R. Botta. 2006. Characterization and genetic relationship of wild species and old garden roses based on microsatellite analysis. J. Amer. Soc. Hort. Sci. 131:66-73.

Seringe, N.C. 1818. Observations générales sur les Roses, p. 2. In: Musée helvétique d'histoire naturelle (part Botanique). tome I. Chez l'auteur, Genève, $\mathrm{CH}$.

Small, R.L., J.A. Ryburn, R.C. Cronn, T. Seelanan, and J.F. Wendel. 1998. The tortoise and the hare: Choosing between noncoding plastome and nuclear $A d h$ sequences for phylogeny reconstruction in a recently diverged plant group. Amer. J. Bot. 85:1301-1315.

Swofford, D.L. 2002. PAUP*4.0b10: Phylogenetic analysis using parsimony (*and other methods), version 4. Sinauer Associates, Sunderland, MA.

Taberlet, P., L. Gielly, G. Pautou, and J. Bouvet. 1991. Universal primers for amplification of three non-coding regions of chloroplast DNA. Plant Mol. Biol. 17:1105-1114.

Takeuchi, S., K. Nomura, H. Uchiyama, and K. Yoneda. 2000. Phylogenetic relationships in the genus Rosa based on the restriction enzyme analysis of the chloroplast DNA. J. Jpn. Soc. Hort. Sci. 69:598-604.

Tang, K.X., X.Q. Qiu, H. Zhang, S.F. Li, Q.G. Wang, H.Y. Jian, B. Yan, and X.Q. Huang. 2008. Study on genetic diversity of some Rosa germplasm in Yunnan based on SSR markers. Acta Hort. Sin. 35:1227-1232 [in Chinese with English abstract].

Thompson, J.D., T.J. Gibson, F. Plewniak, F. Jeanmougin, and D.G. Higgins. 1997. The clustal X windows interface: Flexible strategies for multiple sequence alignment aided by quality analysis tools. Nucl. Acids Res. 25:48764882 .

Thory, C.A. 1820. Prodrome de la monographie des espèces et variétés connues du genre rosier, divisées selon leur ordre naturel, p. 128. P. Dufart, Paris, France.

Wissemann, V. 2003. Conventional taxonomy of wild roses, p. 111-117. In: A. Roberts, T Debener, and S. Gudin (eds.). Encyclopedia of rose sciences. 1st ed. Elsevier Science, Oxford, UK.
Wissemann, V. and C.M. Ritz. 2005. The genus Rosa (Rosoideae, Rosaceae) revisited: Molecular analysis of nrITS-1 and atpB-rbcL intergenic spacer $(I G S)$ versus conventional taxonomy. Bot. J. Linn. Soc. 147:275-290.

Wu, S., Y. Ueda, H.Y. He, S. Nishihara, and S. Matsumoto. 2000. Phylogenetic analysis of Japanese Rosa species using matK sequences. Breeding Sci. 50:275-281.

Wu, S., Y. Ueda, S. Nishihara, and S. Matsumoto. 2001. Phylogenetic analysis of Japanese Rosa species using DNA sequences of nuclear ribosomal internal transcribed spacers (ITS). J. Hort. Sci. Biot. 76:127-132.

Wylie, A.P. 1954. The history of garden roses. J. Roy. Hort. Soc. 79:555-571.

Young, M.A. and P. Schorr. 2007. Modern roses XII. The American Rose Society, Shreveport, LA.

Zhu, Z.M., X.F. Gao, and M. Fougère-Danezan. 2015. Phylogeny of Rosa sections Chinenses and Stynstylae (Rosaceae) based on chloroplast and nuclear markers. Mol. Phylogenet. Evol. $87: 50-64$. 